\title{
Consolidation of Ancient Raw Materials Using a Reversible, Elastic, Soft Polymer
}

\author{
Juan Manuel Navarrete ${ }^{1}$, Gustavo Leonardo Martínez $^{2 \dagger}$ \\ ${ }^{1}$ Inorganic and Nuclear Chemistry Department, Faculty of Chemistry, National University of Mexico, Mexico City, Mexico \\ ${ }^{2}$ National Coordination to Restore the Cultural Inheritance, National Institute of Anthropology and History, Mexico City, Mexico \\ Email: jmnat33@unam.mx
}

Received November 17, 2011; revised December 3, 2011; accepted January 8, 2012

\begin{abstract}
Aging of ancient raw materials usually finish with disintegration, which starts on surface of walls to progress toward the inside mass of a huge variety of mineral compounds. This is particularly harmful when antique buildings keep mural paintings, which suffers destruction before the wall itself. Same case appears on sculptures and monuments, whose surfaces are often attacked by living organisms which start a deterioration process previous to complete disintegration. The main factor to produce these unwanted effects is humidity, either rain for materials exposed to open air, or underground humidity going up by capillarity of minerals, in this case represented by porosity of associated salts forming the material. This paper describes a method to measure easily the relative porosity of diverse raw materials at laboratory level, by using a radioactive labeled solution, and also a procedure to reduce their porosity of those minerals. The efficiency of this procedure is measured in the same way, and so the results obtained at laboratory level have encouraged its use at real scale, where it has been quite successful for a number of materials in a limited span of five years.
\end{abstract}

Keywords: Consolidation; Preservation; Humidity; Ancient; Materials

\section{Introduction}

Ancient raw materials are usually attacked from two fronts: one is from outside, mainly by rain, snow, dust, wind, light and severe temperature changes, other is from inside, mainly by underground humidity which goes up through wall porosity, as a solution carrying on a great variety of salts. When both fronts meet, destructive conditions for raw materials become most powerful, but just one front is enough to deteriorate and finally destroy bricks, volcanic stones, rocks, feldspars, clays, adobes and so on. Even at controlled room conditions of temperature and humidity, such as those in museums, just at the time goes by materials surface start a more or less visible process of aging. However, as humidity and unstable temperature are the most common causes of destruction, and underground humidity is very difficult to control or shield efficiently in ancient buildings, it is proposed here to use at laboratory level a very easy and simple method to measure first the absorption capacity or porosity in samples of Mexican ancient raw materials, in order to determine a decreasing factor when the samples have been permeated with an organic gelatin solution, added with two food preservatives (sodium benzoate and potassium sorbide) plus a very strong organic preservative (37\% formaldehyde solution). These additives guarantee that gelatin will not become a fungus or bacteria culture as time goes by, and by other part form a tougher polymer, much more insoluble in water than plain gelatin, but still soluble in hot water $\left(60^{\circ} \mathrm{C}\right)$ [1]. Applied at real scale, this simple technique has showed till now a surprising efficiency in every material tested during a limited span of five years.

\section{Materials and Methods}

As sodium sulfate is a very common salt found in solid deposits on ancient walls [2], this salt was chosen to be labeled with radioactive ${ }^{22} \mathrm{Na}$ (half life 2.6 years, annihilation peak of $0.511 \mathrm{MeV}$ of energy). A radioactive solution was made, $0.1 \% \mathrm{Na}_{2} \mathrm{SO}_{4}$ concentration and ${ }^{22} \mathrm{Na}$ radioactivity about $30 \mathrm{~Bq} / \mathrm{ml}$. Samples were collected from debris found in archeological sites of interest such as: Teotihuacan, Tula, Palenque, Veracruz and Bonampak. They were cut in smaller samples prisms of about 3 $\mathrm{cm}$ height and $1 \mathrm{~cm}$ wide, which were cleaned and weighed.

Then, prisms were placed on a disposable tray divided by squares, where $2 \mathrm{ml}$ per square of the labeled solution had been previously deposited, in order to get approximately $1-2 \mathrm{~cm}$ over the prism base (Figure 1). In half an hour samples were totally wet by the labeled solution. They were isolated from the radioactive solution and dried at room temperature during 24 hours. Sodium sul- 
fate salt was deposited on the surfaces. They were carefully cleaned wearing gloves and manipulating a spatula, before being conditioned to be detected either in test tubes or plastic bags (Figures 2 and 3). Samples were detected and counts accumulated during 10 to 30 minutes. Detector used was a well type $3 \times 3$ ” solid scintillator NaI (Tl), Bicron trade mark, coupled to a PC charged with the Maestro program for radioactive detection. Counts accumulated per time and weight unit represent in relative terms their different porosity from one to another material, and in consequence its ability to absorb humidity, either from soil, or in open air conditions from the environment, both equally destructive. These differences were as much as a factor of ten for different materials (porous volcanic stones and feldspar), and till 25\% for different samples of same material, because materials are far from being quite homogeneous. After the relative measurement of porosity in different raw materials was performed, same type of prism samples were permeated with a warm solution $(5 \%)\left(60^{\circ} \mathrm{C}\right)$ of organic powdered

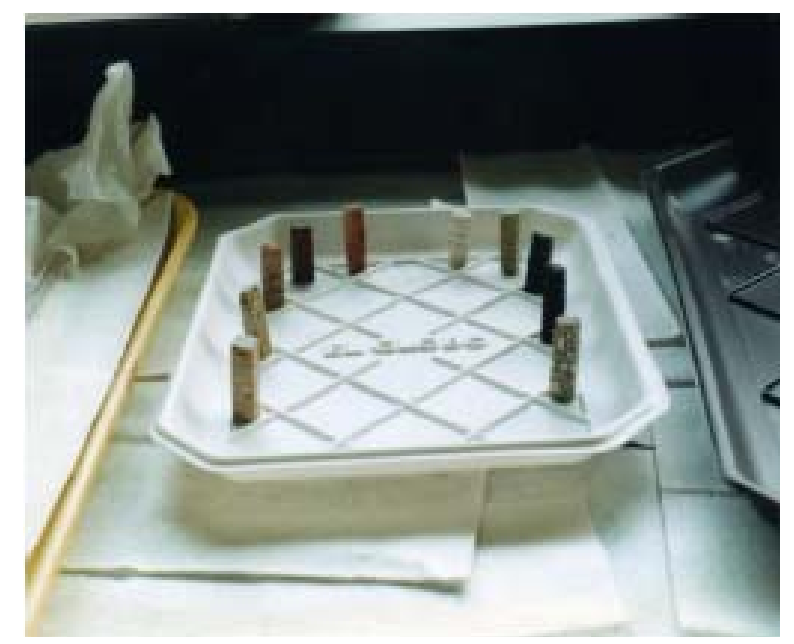

Figure 1. Samples of different materials conditioned to absorb the labeled solution.

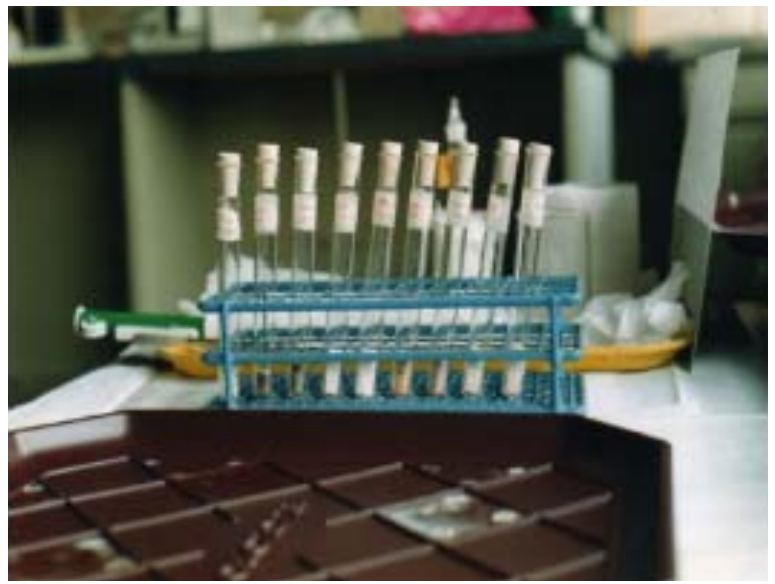

Figure 2. Samples conditioned in test tubes to be detected. gelatin, so called French gelatin, plus two food preservatives A.R.: sodium benzoate and potassium sorbate $(2.5 \%$ each) (Figure 4).

After 3 hours, when the gelatin is not solid yet, and the material looks humid and brilliant, by using one hand sprinkler, gloves and a mask protector, was added 37\% formaldehyde aqueous solution, one tenth to one fifth of the gelatin volume solution previously made. Tougher gelatin is formed overnight. When next day the porosity of same materials was tested by means of the radioactive solution, in exactly the same way that samples with no gelatin treatment, after carefully cleaning from external gelatin residues, the difference was dramatic. From $70 \%$ to $0 \%$ of counts accumulated, that is to say, from $30 \%$ to $100 \%$ of porosity reduction, according the nature of the material tested. An inverse relation was found between the porosity of samples and efficiency with gelatin treatment. So, plain dry mud, adobe, calcareous and porous volcanic stones, showed a total blockade to labeled solution at laboratory conditions, while less porous material such as dolomite and feldspar showed an absorption rate about 30\% lower than before treatment. Some other raw

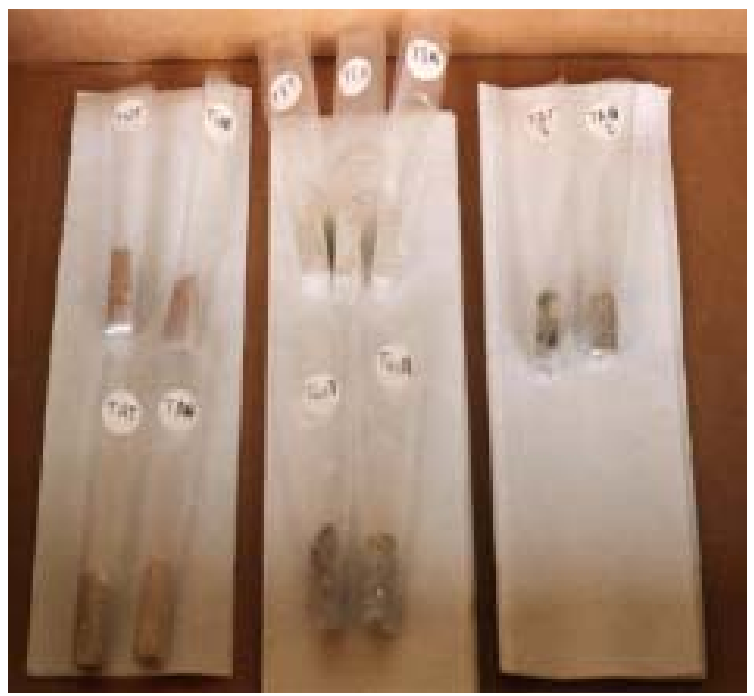

Figure 3. Samples conditioned in polyethylene bags to be detected.

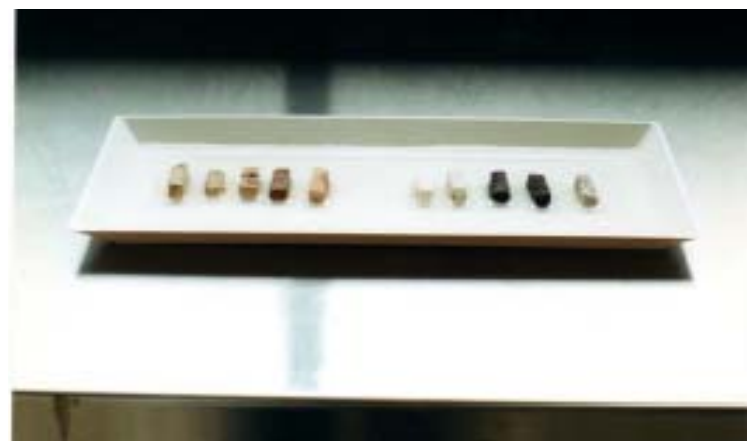

Figure 4. Samples absorbing gelatin. 
materials such as brick, clay, limestone and assorted volcanic stones showed intermediate results. A piece of gelatin obtained in the described way, was immersed in plain water at room temperature. After one month begun to be slightly soluble, but after two years was not completely dissolved. On the contrary, by using water at $60^{\circ} \mathrm{C}-70^{\circ} \mathrm{C}$ it was soluble in one hour. Also, another test was made at laboratory level, using a colored methyl red aqueous solution. Two adobe bricks were permeated with the colored solution in identical conditions: one treated with the gelatin on just one surface, that opposite to liquid permeation, while the other brick was untreated.

The non treated brick got wet till the top in few minutes, becoming dark red with the solution, sticking easily on it a piece of tissue paper, while the other one remained one month with periodical replacement of solution lost by evaporation, with no color on the top surface and of course non sticking any piece of tissue paper (Figure 5). Nevertheless, the application of the technique at real scale is quite another matter, since conditions of volume, time and humidity persistence, either external or internal by underground humidity, are enlarged beyond any proportion compared with those of laboratory level. In this way, permeation of gelatin has been used in some Mexican monuments and whole objects always following the next recipe:

1) First, to clean up the surface in the usual way with water, brush and soft detergent. Once dry, sprinkle the gelatin solution (5\%) plus food preservatives, sodium benzoate and potassium sorbide ( $2.5 \%$ each) at a temperature about $60^{\circ} \mathrm{C}-70^{\circ} \mathrm{C}$. Application must be as homogeneous as possible on the surface, avoiding slipping down of the solution, which means to wait some seconds to allow the warm liquid permeates the porosity of material. Sprinkler managed by hand was preferred to those running by a compressor, because it is easier to avoid the slipping down of the solution, and warm temperature of it is much better kept, which means larger absorption in

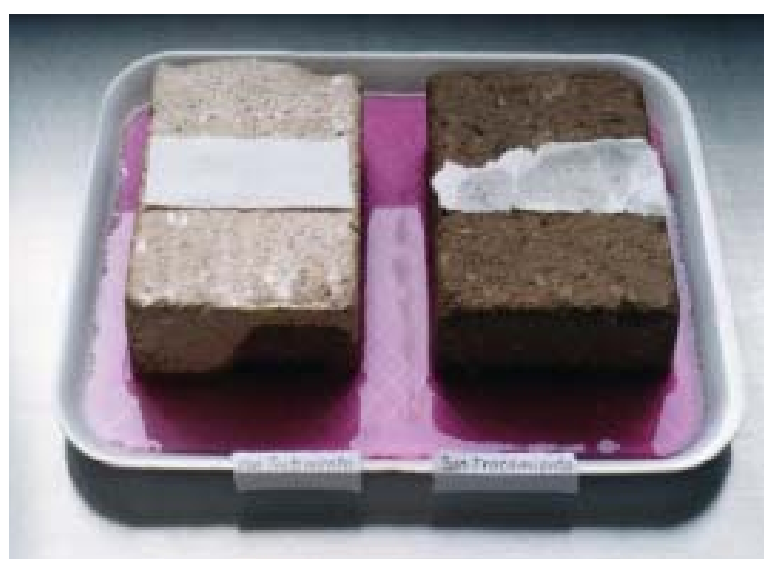

Figure 5. Bricks with and without treatment, absorbing colored solution. the material. Yielding of solution is a function of material porosity, but a suitable average seems to be $2 \mathrm{~L} \cdot \mathrm{m}^{-2}$.

2) After about three hours, gelatin begins to solidify and material looks humid and brilliant. Then it must be sprinkled with $37 \%$ formaldehyde solution, in a proportion $10 \%$ to $20 \%$ in volume applied of gelatin solution. The hand sprinkler was used again, wearing a protective mask, to avoid inhalation of formaldehyde vapors. Both solutions can not be mixed at the start of process, because then gelatin does not become solid at any time. Instead, a tougher polymer, more insoluble in cold water is formed, just adding the formaldehyde when gelatin begins to condensate. Treatment is finished by cooling overnight. Material surface is protected by an interior layer of tough gelatin, against humidity from rain at open air conditions, as well as underground humidity and its dissolved salts, being quite inert to any change in a reasonable time span.

\section{Results}

First, the method has been applied on a plastered wall located in Teotihuacan archeological zone [3].

It is roofed, but extremes and front are open. Conditions of maintenance were rather precarious (Figure 6). After longer than five years, salts deposition has been completely interrupted, and not fungus mushrooms, or some other culture of organic material has appeared on it. A small rabbit made out from volcanic stone during the Aztec empire period, at open air conditions for indefinite time, was treated and placed as before [4]. Conservation has lasted longer than five years with no problem (Figures 7 and 8). Five calcareous stone Maya pieces sent to be exposed in European countries, showed an evident loss of powder material when they were manipulated and conditioned for the trip, even when they have always been at museum conditions. After treatment, manipulation was made with no material loss and treatment was quite unnoticeable (Figures 9 and 10).

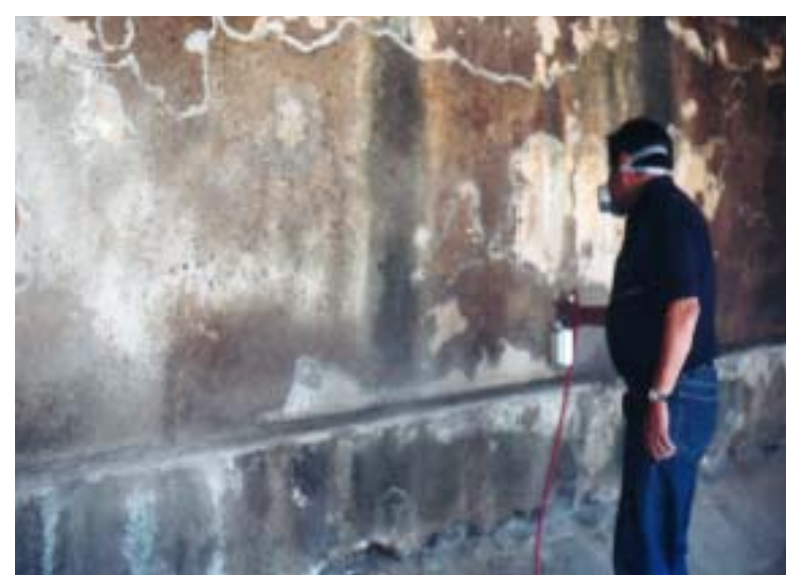

Figure 6. Wall in Teotihuacan region under treatment. 


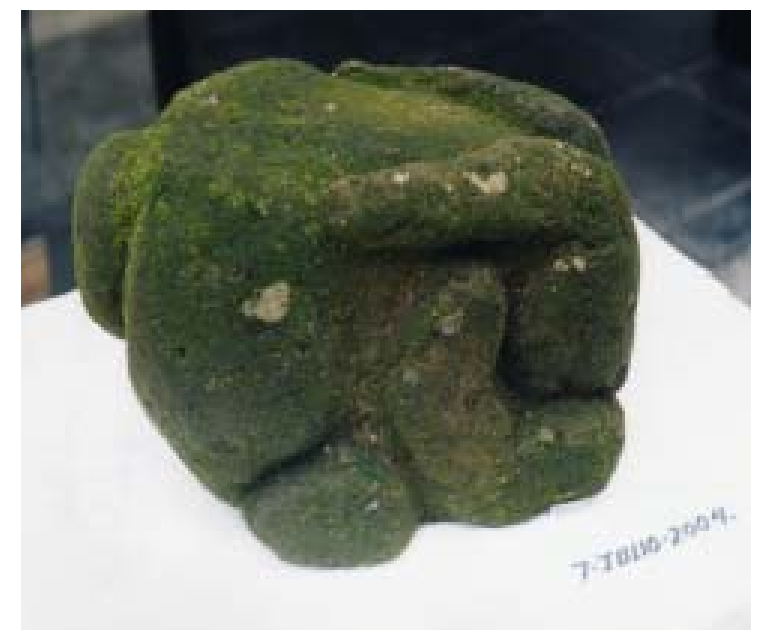

Figure 7. Aztec little rabbit after years at open air conditions.

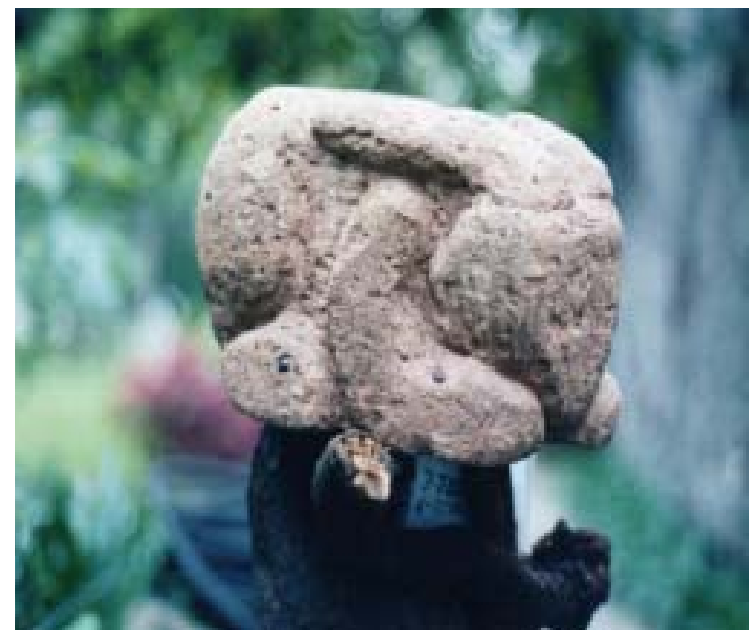

Figure 8. Aztec little rabbit after longer than five years treatment.

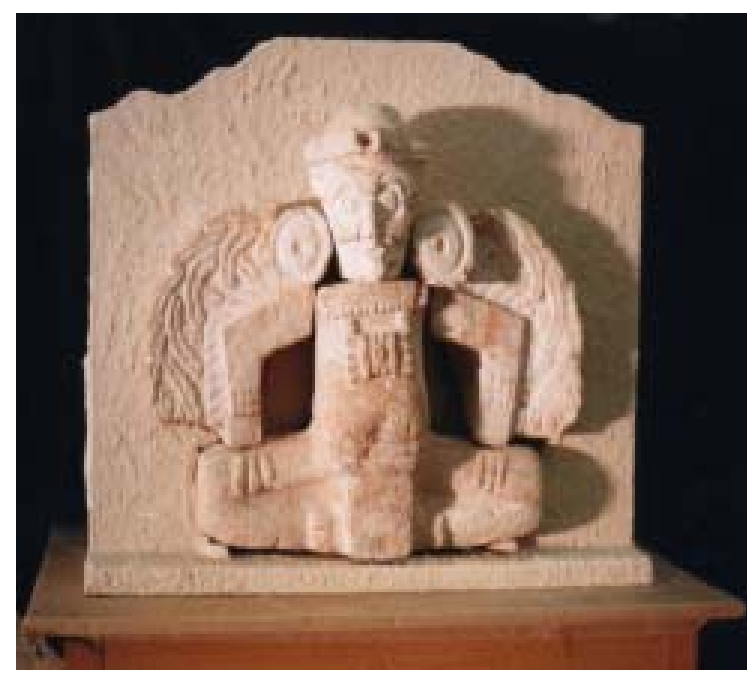

Figure 9. Mayan representation after treatment for travelling to Europe.

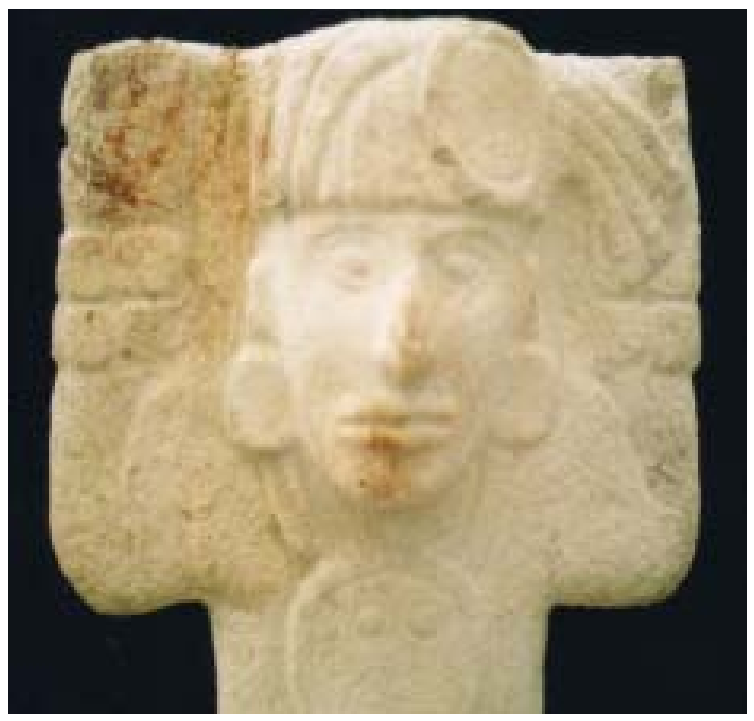

Figure 10. Another Mayan piece ready to be transported after treatment.

A jaguar sculpted on one piece of very porous volcanic stone, in the Tula region, lost its right paw in unknown circumstances, but its left paw became thinner and very fragile, even when it has been at museum conditions for very long time. Disintegration of material with just hand touch was evident. After treatment, it can be manipulated just with some care, left paw remains thin but much firmer than before, and it seems that at museum conditions it is going to be well preserved for many years (Figure 11). In the same archeological region and museum, an oven or furnace, probably used at underground conditions, was untouchable because the plain dried mud of its material was then quite loosed, being impossible to transport it to some other location for the great risk of total disintegration. The method was applied with success, and now it is just another museum piece perfectly transportable (Figures 12 and 13). Finally, an image of our Lady of Guadalupe, painted in 1885 on a plastered wall, under roof but in an open corridor at both extremes, was almost completely destroyed by internal humidity, both underground and broken pipes. Pigments lost cohesion with the plaster, and plaster with the wall. So, gelatin was used in every step of restoration. It was possible to cut out the whole picture from the wall, in order to be transported to restoration workshop, plaster was replaced and painted on it, finishing was also made with gelatin solution, and now it is in the same place, but in a niche behind a glass (Figures 14 and 15).

\section{Discussion}

Experimental results obtained at laboratory level for relative humidity absorption by materials and the way to avoid it, have been very useful when the proposed me- 


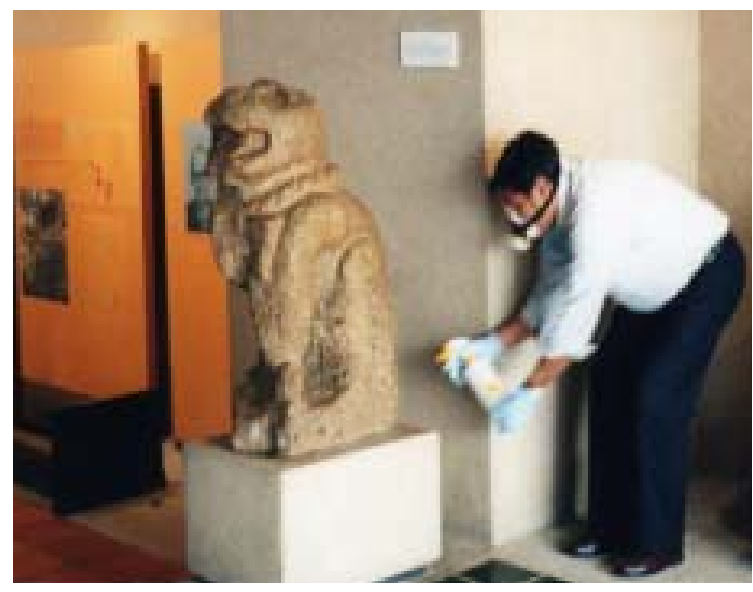

Figure 11. Tula region's jaguar under treatment.

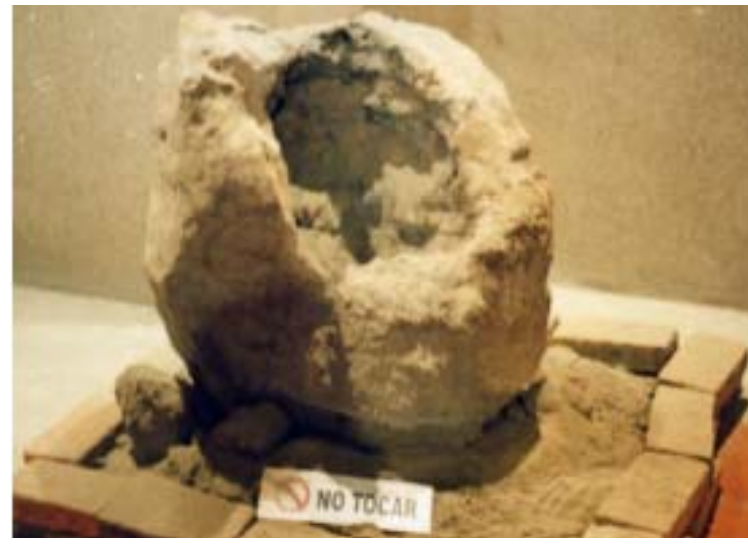

Figure 12. Tula region's oven before treatment.

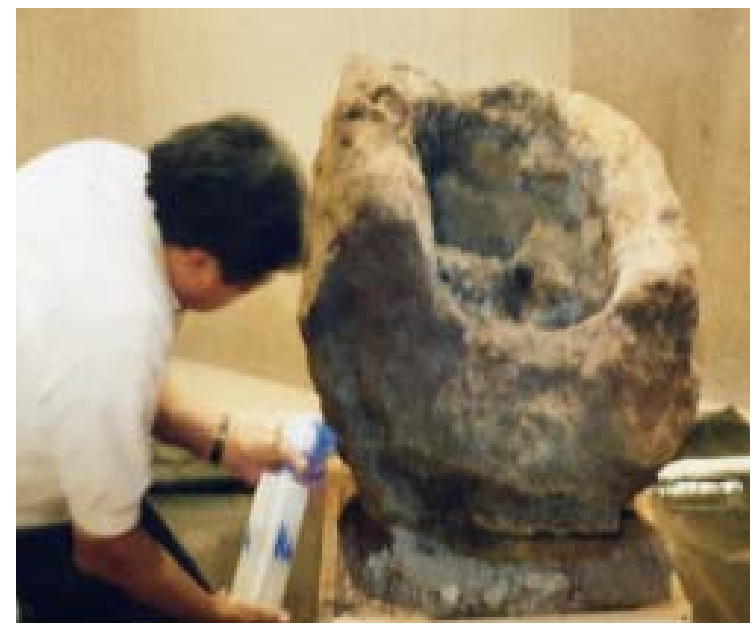

Figure 13. Tula region's oven under treatment.

thod has been applied at real scale, even when five years is a very short span to test it. However, the fact that it can be applied periodically, and also that gelatin can be removed easily by hot water $\left(60^{\circ} \mathrm{C}-70^{\circ} \mathrm{C}\right)$, if its evolution were undesirable, which has not been the case till now, seem to be so attractive characteristics as the easiness,

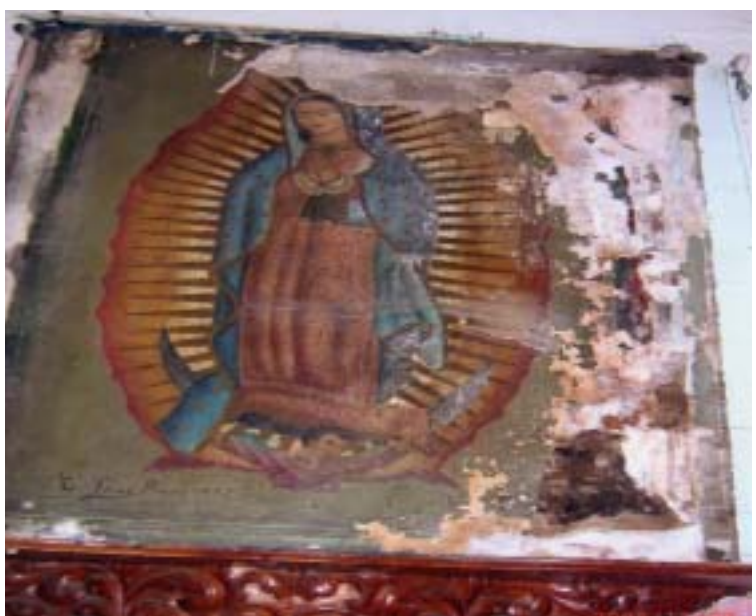

Figure 14. Virgin of Guadalupe's image before treatment.

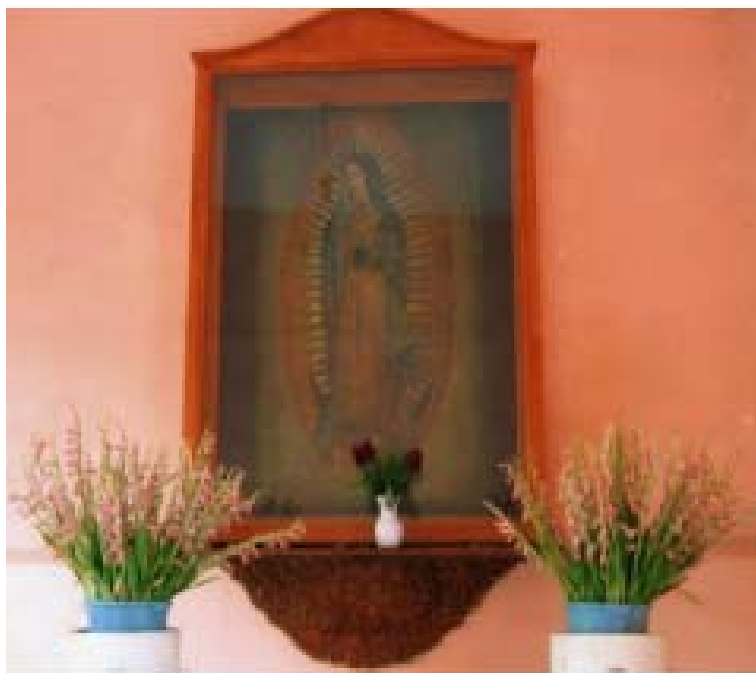

Figure 15. Virgin of Guadalupe’s image after treatment.

almost non visible and time saving to perform it. As a matter of fact, it seems that clogging porosity with a soft, elastic and compressible material such as gelatin, charged with two food preservatives and one very strong preservative of organic material, such as formaldehyde, differs greatly from clogging porosity with a tough, insoluble and in some way as biodegradable as the material under conservation.

\section{Conclusion}

The proposed method has worked all right, either to avoid underground and environmental humidity, as to consolidate loose materials. Promising results as they are, suggest trying on for size the method in truly big restoration projects. Just to mention few examples: recently discovered painted walls of Cacaxtla in Mexico, as well as Hagia Sophia in Turkey, for underground humidity, and Xian's warriors in China, to consolidate material. 


\section{REFERENCES}

[1] Merck and Co. Inc., "The Merck Index," 9th Edition, Whitehouse Station, Hunterdon County, 1976, p. 4096.

[2] H. Rosch and J. Schwarz, "Damaged to Frescoes Caused by Sulphate-Bearing Salts: Where Does the Sulphur Come from?” Studies in Conservation, Vol. 38, No. 4, 1993, pp. 224-230. doi:10.2307/1506367

[3] G. L. Martinez and J. M. Navarrete, "Use of a Radiotracer to Test and Reduce the Porosity and Humidity Absorption from the Soil in Pre-Hispanic Raw Materials,” Journal of Radioanalytical and Nuclear Chemistry, Vol. 263, No. 1, 2005, pp. 35-38. doi:10.1007/s10967-005-0008-2

[4] G. L. Martinez and J. M. Navarrete, “A New Technique to Preserve Raw Materials of Ancient Monuments against the Humidity and Its Test Using ${ }^{22}$ Na Labelled Solutions," Journal of Radioanalytical and Nuclear Chemistry, Vol. 274, No. 3, 2007, pp. 651-655. doi:10.1007/s10967-007-7097-z 